\title{
The role of bevacizumab in targeted vascular endothelial growth factor therapy for epithelial ovarian cancer: an updated systematic review and meta-analysis
}

This article was published in the following Dove Press journal:

OncoTargets and Therapy

\section{Guanyu Ruan ${ }^{1, *}$ \\ Lixiang $\mathrm{Ye}^{2, *}$ \\ Guifen Liu ${ }^{3}$ \\ Jian $\mathrm{An}^{3}$ \\ Jalid Sehouli ${ }^{4}$ \\ Pengming Sun ${ }^{1,3}$}

'Laboratory of Gynecologic Oncology, Fujian Provincial Maternity and Children's Hospital, Affiliated Hospital of Fujian Medical University, ${ }^{2}$ Fujian Center for Safety Evaluation of New Drugs, Fujian Medical University, ${ }^{3}$ Department of Gynecology, Fujian Provincial Maternity and Children's Hospital, Affiliated Hospital of Fujian Medical University, Fuzhou, People's Republic of China; ${ }^{4}$ Department of Gynecologic Oncology and Gynecology, Charité Campus VirchowKlinikum, European Competence Center for Ovarian Cancer, University of Berlin, Berlin, Germany

*These authors contributed equally to this work
Correspondence: Pengming Sun Laboratory of Gynecologic Oncology, Fujian Provincial Maternity and Children's Hospital, Affiliated Hospital of Fujian Medical University, No 18 Daoshan Road, Gulou District, Fuzhou, Fujian 32000I,

People's Republic of China

Tel +86 59l 87558732

Fax +86 59| 8755 I247

Email fmsun1975@fjmu.edu.cn

\begin{abstract}
The impact of bevacizumab (an anti-vascular endothelial growth factor therapy) remains uncertain, which has been the focus of studies on the management of epithelial ovarian cancer (EOC). To investigate the efficacy of bevacizumab combinations with different regimens in the treatment of patients with EOC, a meta-analysis of Phase III randomized controlled trials was conducted. The databases searched included PubMed, Embase, ClinicalTrials.gov, Chinese Knowledge Infrastructure, as well as the Cochrane Central Register of Controlled Trials. After evaluation of quality, a meta-analysis of valid extracted data was performed using Review Manager (RevMan) software. Five studies with 4,369 patients were included. Bevacizumab plus chemotherapy improved progression-free survival (hazard ratio $[\mathrm{HR}]=0.63 ; 95 \%$ confidence interval $[\mathrm{CI}], 0.51-0.77 ; P<0.01)$ and overall survival $(\mathrm{HR}=0.91 ; 95 \% \mathrm{CI}, 0.84-0.99$; $P<0.05)$. Interestingly, in patients with a high risk of progression, the subgroups that received bevacizumab combined with different regimens of chemotherapy showed a significant improvement with paclitaxel plus carboplatin-based chemotherapy (HR $=0.86 ; 95 \% \mathrm{CI}, 0.77-0.95$; $P<0.01$ ), but not with non-paclitaxel plus carboplatin-based chemotherapy ( $\mathrm{HR}=0.91 ; 95 \%$ CI, $0.77-1.07 ; P>0.05$ ) in overall survival. The combination of bevacizumab and paclitaxel plus carboplatin-based regimens offers a new treatment option for women with EOC, especially in those with a high risk of progression.
\end{abstract}

Keywords: epithelial ovarian cancer, bevacizumab, overall survival, chemotherapy, metaanalysis, systematic review

\section{Introduction}

Epithelial ovarian cancer (EOC), the most lethal gynecologic cancer, is responsible for approximately 52,000 new cases and 22,000 deaths in People's Republic of China and 22,000 new cases and 14,000 deaths in the USA annually. ${ }^{1,2}$ Due to its vague and mimetic symptoms, nearly $75 \%$ of patients with EOC are diagnosed at advanced stages and are associated with high mortality and morbidity rates at the time of initial diagnosis. For almost 15 years, the standard primary treatment for EOC has been cytoreductive surgery, followed by a combination chemotherapy of platinum and paclitaxel. ${ }^{3}$ Despite high initial rates of response to first-line therapy, more than $70 \%$ of patients with EOC relapse within 5 years due to drug resistance. The effect of subsequent chemotherapy for recurrent EOC is marginal and especially poor in platinum-resistant settings. ${ }^{4}$

Angiogenesis plays a fundamental role in normal ovarian physiology, as well as in the pathogenesis of ovarian cancer. ${ }^{4}$ Vascular endothelial growth factor (VEGF) is 
the best-characterized angiogenic factor and is recognized as a major element in regulating angiogenesis. ${ }^{5}$ Increased VEGF expression has been associated with tumor progression and poor overall survival (OS). ${ }^{6}$ Bevacizumab (Avastin ${ }^{\circledR}$; Roche, Basel, Switzerland), the first anti-VEGF monoclonal antibody found to be active in EOC, has been demonstrated to provide significant improvements in preclinical studies, case series, and several clinical trials. ${ }^{7-10}$ Most recently, four randomized controlled trials (RCTs) have been carried out adding bevacizumab to either frontline chemotherapy (GOG- $0218^{11}$ or ICON7 ${ }^{12}$ ), or to chemotherapy in "platinum-resistant" (AURELIA ${ }^{13}$ ) or "platinum-sensitive" (OCEANS ${ }^{14}$ ) recurrent EOC. A fifth randomized Phase III trial has also been presented. ${ }^{3}$ Although all studies have reported prolonged progression-free survival (PFS), only two suggested a clinical improvement in OS among predefined subgroups in exploratory analyses. ${ }^{3,13}$ Furthermore, the efficacy of combining chemotherapeutic regimens is also controversial. Whether paclitaxel and carboplatin (PC) is better than other chemotherapeutic agents as a companion for bevacizumab remains a critical question.

In this article, we systematically review published data and comprehensively analyze and integrate all published Phase III RCTs to evaluate the efficacy of bevacizumab combinations with different regimens, regardless of first-line treatment or recurrent disease, in patients with EOC.

\section{Materials and methods Publication search}

This study was performed with the checklist from the Preferred Reporting Items for Systematic Reviews and MetaAnalyses (PRISMA) guidelines. ${ }^{15}$ The criteria for inclusion were as follows: 1) prospective RCTs studying bevacizumab in patients with EOC, 2) bevacizumab added as maintenance therapy after chemotherapy, or concurrently with chemotherapy followed by a maintenance period, 3) RCTs reporting the numbers of patients with hazard ratios (HRs) and 95\% confidence intervals (CIs) of PFS and OS or presenting sufficient data for calculating HRs with 95\% CIs, 4) RCTs reporting the numbers of patients with toxicity or adverse events, and 5) language limited to English or Chinese. Our final search concluded with literature published on or before June 26, 2017. Two independent researchers (GR and LY) retrieved the PubMed, Embase, Chinese Knowledge Infrastructure (CNKI), and the Cochrane Central Register of Controlled Trials (CENTRAL) databases for the following search terms: "epithelial ovarian cancer" and "bevacizumab". In addition, all relevant references of included trials, review articles, editorials, and abstracts presented at the annual meetings of the European Society of Medical Oncology, the International Gynecologic Cancer Society, and the American Society of Clinical Oncology (ASCO) were also manually searched. Registers of clinical trials (ClinicalTrials.gov) were also searched.

\section{Quality assessment and data extraction}

All quality assessments and data extractions were conducted independently by two researchers (GR and LY), and in case of inconsistent selection, a third author (PS) participated in data selection. The Cochrane Collaboration's tool for assessing risk of bias was used to assess study quality. ${ }^{16}$ This included the following assessments: randomized sequence generation, allocation concealment, blinding of participants and personnel, blinding of outcome assessment, incomplete outcome data, selective reporting, and other biases. Items in the risk of bias assessment were judged as "low-risk" (+), "unclear" (?), or "high-risk" (-) for each study. For each trial, the following details were included: first author's name, publication year, country of origin, trial phase, diagnostic criteria, sample size, regimens, PFS, OS, and adverse events.

\section{Statistical analysis}

Statistical heterogeneity was explored using a chi-square test $^{17}$ and expressed as an $I^{2}$ index (a significance level of $P<0.10)$. $I^{2}$ values over $50 \%$ represented substantial heterogeneity. ${ }^{18}$ If there was no heterogeneity, a fixed effects model was used for meta-analysis; otherwise, a random effects model based on the DerSimonian and Laird estimator was used. ${ }^{17} \mathrm{HRs}$ and their $95 \%$ CIs of all the included trials for time-to-event data for generic inverse variance data were calculated by determining the weighted average of individual study results. Results are presented in Figure 3 as forest plots, where an HR value of $<1$ indicated a benefit for the inclusion of bevacizumab. A two-sided $P<0.05$ was considered statistically significant. Potential publication bias was tested with a funnel plot. Subgroup meta-analyses were performed by treatment regimen (PC or non-PC). All analyses were performed with Review Manager (RevMan) software, version 5.3 (Update Software Ltd, Oxford, Oxon, UK).

\section{Results}

\section{Characteristics of eligible studies}

Our search yielded a total of 283 records after excluding duplicates. We excluded 243 records based on the information presented in the title or abstract and 32 records based on the information presented in the full text. Finally, five Phase III RCTs met our inclusion criteria for meta-analysis, 


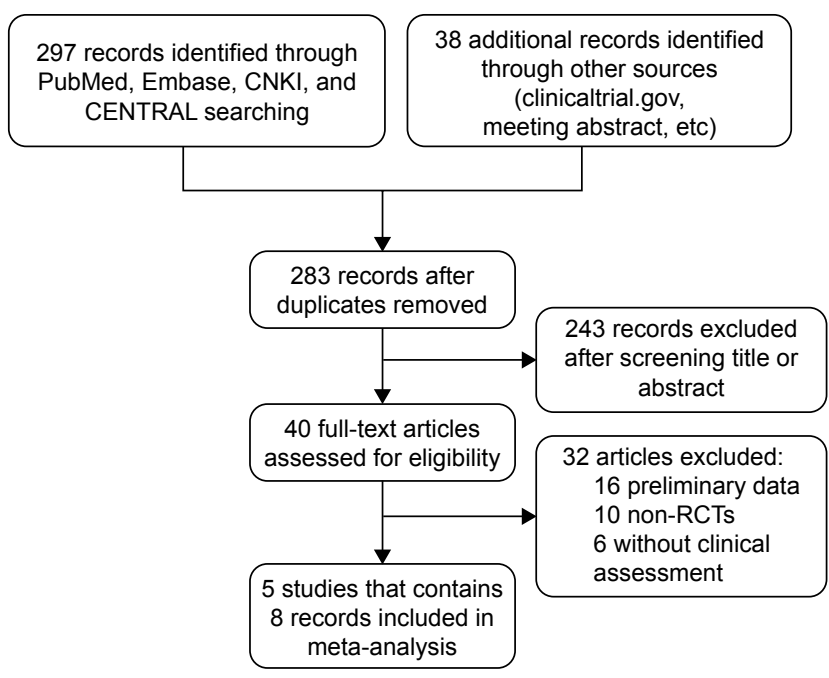

Figure I Flow diagram of the literature search and selection process. Abbreviations: CNKI, Chinese Knowledge Infrastructure; CENTRAL, Cochrane Central Register of Controlled Trials; RCT, randomized controlled trial.

including eight records..$^{3,11-14,19-21}$ In total, 4,994 patients were included in the assessment of PFS, OS, and toxicity. Figure 1 shows the detailed steps of our literature selection procedure, and Table 1 shows the main characteristics of all RCTs included in this meta-analysis. The Burger 2010 (GOG-0218) trial included multiple treatment groups (threearm trial), and to reduce heterogeneity, we recruited only the bevacizumab-throughout group. Accordingly, we divided the control group between the treatment groups and treated comparisons between each treatment group and a split control group as independent comparisons. This was not necessary for PFS or OS as we obtained HR estimates from a Cox regression model. Finally, a total of 4,369 patients were included in the pooled analyses.
Five published studies ${ }^{3,11-14}$ showed a low risk of bias in randomized sequence generation, allocation concealment, incomplete outcome data, selective reporting, and other biases; meanwhile, blinding exhibited a low risk of bias in two published studies ${ }^{11,14}$ and was unclear in three open-label published studies. ${ }^{3,12,13}$ Figure 2 illustrates the general risk of bias across the included studies.

\section{PFS}

A total of five trials reported PFS, representing 4,369 patients. $^{3,11-14}$ There was significant heterogeneity between the trials $\left(I^{2}=86 \%\right.$; chi-square $\left.=28.58 ; P<0.01\right)$. Figure $3 \mathrm{~A}$ shows that the combination of bevacizumab and chemotherapy resulted in a statistically significant improvement in PFS, compared with chemotherapy alone $(\mathrm{HR}=0.63 ; 95 \%$ CI, 0.51-0.77; $\mathrm{Z}=4.55, P<0.01)$. The funnel plot showed no potential publication bias (Figure 4A). The subgroup analysis based on the regimen of chemotherapy in Figure $3 \mathrm{~A}$ showed that the addition of bevacizumab to chemotherapy for EOC led to a statistically significant improvement in PFS, both in PC-based chemotherapy (HR $=0.73$; 95\% CI, $0.63-0.85 ; \mathrm{Z}=4.0, P<0.01)$ and in non-PC-based chemotherapy $(\mathrm{HR}=0.48 ; 95 \% \mathrm{CI}, 0.41-0.57 ; \mathrm{Z}=8.91, P<0.01)$. Similar results were also found in patients with a high risk of progression (International Federation of Gynecology and Obstetrics (FIGO) stage IV or III disease and $>1.0 \mathrm{~cm}$ of residual disease after debulking surgery), as presented in Figure 3C.

\section{OS}

A total of five trials reported OS, representing 4,369 patients..$^{3,11,13,19,20}$ There was no significant heterogeneity

Table I Characteristics of included studies

\begin{tabular}{|c|c|c|c|c|c|c|}
\hline Study & Diagnostic criteria & GOG/ECOG PS & Setting & $\mathbf{n}$ & Treating arm & $\begin{array}{l}\text { Median age } \\
\text { (range) }\end{array}$ \\
\hline \multirow[t]{3}{*}{ GOG-0218 10,11} & GOG & GOG PS 0-2 & First-line and & 625 & P + C + PL; PL maintenance & $60(25-86)$ \\
\hline & & & maintenance & 625 & $\mathrm{P}+\mathrm{C}+\mathrm{Bev} ; \mathrm{PL}$ maintenance & $60(24-88)$ \\
\hline & & & & 623 & $\mathrm{P}+\mathrm{C}+\mathrm{Bev} ;$ Bev maintenance & $60(22-89)$ \\
\hline \multirow[t]{2}{*}{ ICON7 $^{12,20}$} & Local histopathological & ECOG PS 0-2 & First-line and & 764 & $P+C$ & $57(|8-8|)$ \\
\hline & findings & & maintenance & 764 & $\mathrm{P}+\mathrm{C}+\mathrm{Bev} ;$ Bev maintenance & $57(24-82)$ \\
\hline \multirow[t]{2}{*}{ OCEANS ${ }^{14,19}$} & NR & ECOG PS 0-I & $\begin{array}{l}\text { Recurrent, } \\
\text { platinum-sensitive }\end{array}$ & 242 & $\begin{array}{l}\mathrm{G}+\mathrm{C}+\mathrm{P} \text { (combination and } \\
\text { maintenance) }\end{array}$ & $61(28-86)$ \\
\hline & & & & 242 & $\begin{array}{l}\mathrm{G}+\mathrm{C}+\mathrm{Bev} \text { (combination } \\
\text { and maintenance) }\end{array}$ & $60(38-87)$ \\
\hline \multirow[t]{2}{*}{ AURELIA ${ }^{|3,2|}$} & NR & ECOG PS 0-2 & Recurrent, & 182 & PAC or $\mathrm{T}$ or PLD & $61(25-84)$ \\
\hline & & & platinum-resistant & 179 & $\mathrm{PAC}$ or $\mathrm{T}$ or PLD $+\mathrm{Bev}$ & $61(25-80)$ \\
\hline \multirow[t]{2}{*}{ GOG-02133 } & NR & GOG PS 0-2 & Recurrent, & 374 & $P+C$ & 60 \\
\hline & & & platinum-sensitive & 374 & $\mathrm{P}+\mathrm{C}+\mathrm{Bev} ; \mathrm{Bev}$ maintenance & \\
\hline
\end{tabular}

Abbreviations: P, paclitaxel; C, carboplatin; Bev, bevacizumab; G, gemcitabine; T, topotecan; PLD, pegylated liposomal doxorubicin; PAC, weekly paclitaxel; PL, placebo; GOG, Gynaecologic Oncology Group; ECOG, Eastern Cooperative Oncology Group; AUC, area under curve; PS, performance status; NR, not reported. 
A

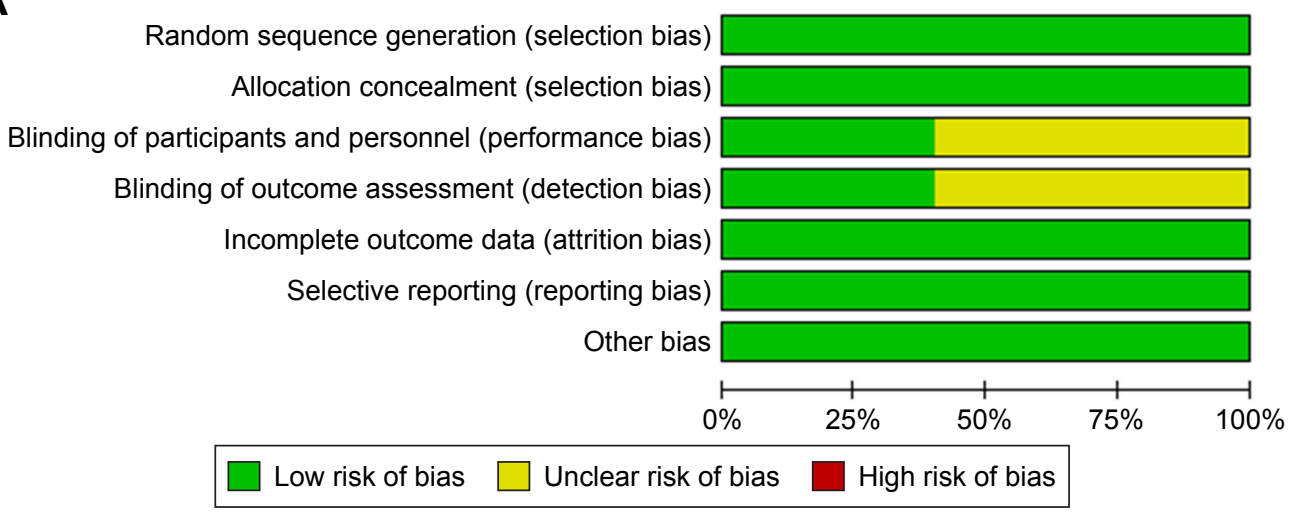

\section{B}

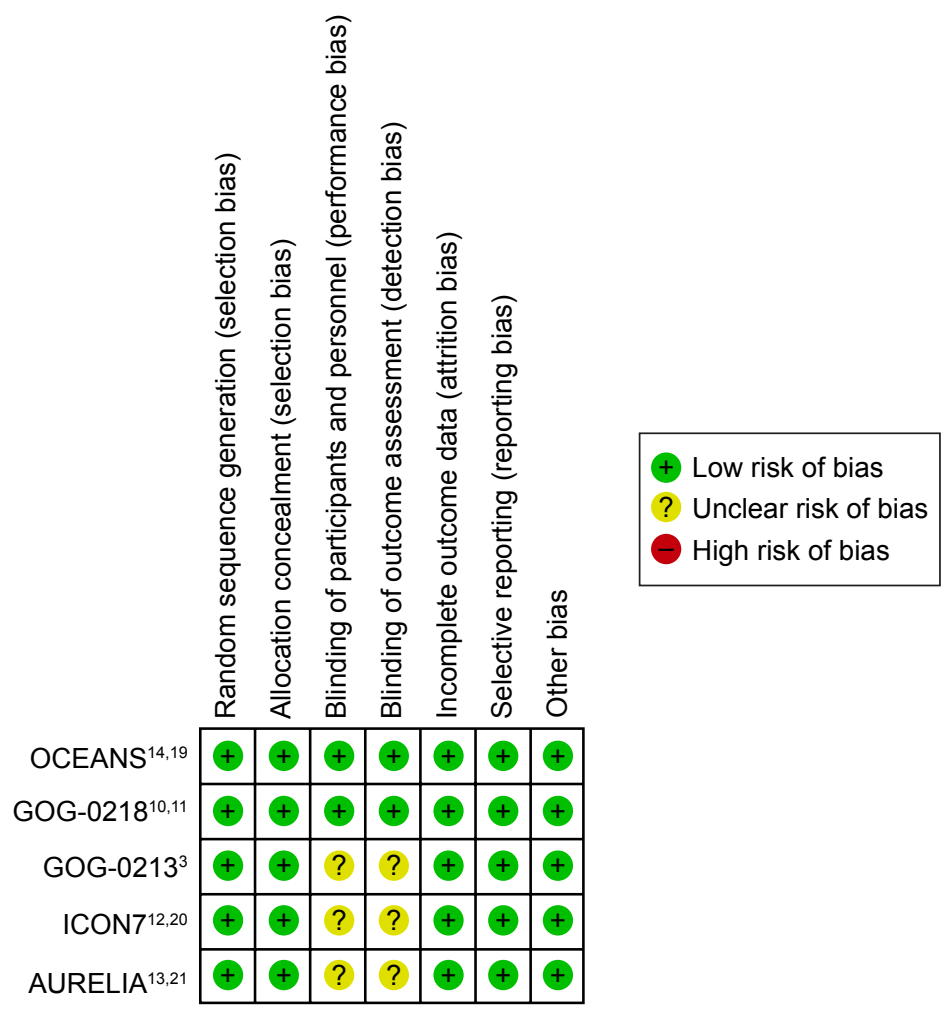

Figure 2 Risk of bias and quality assessment. (A) Risk of bias graph: review authors' judgments about each risk of bias item presented as percentages across all included studies. (B) Risk of bias summary: review authors' judgments about each risk of bias item for each included study.

between the trials $\left(I^{2}=0 \%\right.$; chi-square $\left.=2.70, P>0.10\right)$. Incorporation of bevacizumab resulted in a statistically significant improvement in OS compared with chemotherapy alone $(\mathrm{HR}=0.91 ; 95 \% \mathrm{CI}, 0.84-0.99 ; \mathrm{Z}=2.24, P<0.05)$ in Figure 3B. The funnel plot showed no potential publication bias (Figure 4B). The subgroup that received a combination of bevacizumab with a regimen of chemotherapy showed a trend of improvement without significance ( $\mathrm{HR}=0.91 ; 95 \%$ CI, 0.83-1.00; $Z=1.91, P=0.06$ for PC-based chemotherapy, $\mathrm{HR}=0.91 ; 95 \% \mathrm{CI}, 0.77-1.07 ; \mathrm{Z}=1.16, P=0.25$ for non-PCbased chemotherapy). The subgroup analysis in patients with a high risk of progression based on the regimen of chemotherapy in Figure 3D showed that the addition of bevacizumab to chemotherapy led to a statistically significant improvement in OS in PC-based chemotherapy ( $\mathrm{HR}=0.86$; 95\% CI, 0.77-0.95; $\mathrm{Z}=2.82, P<0.01)$. However, similar results were not found in non-PC-based chemotherapy (HR $=0.91 ; 95 \%$ CI, 0.77-1.07; $\mathrm{Z}=1.16, P>0.05)$.

\section{Discussion}

The standard treatment of EOC since the 1990s has been a combination of platinum and taxane. Since then, only marginal improvements have been made, in variations to chemotherapy dosing, scheduling, and the route of administration, 
in either a frontline or a recurrent setting. ${ }^{4}$ Angiogenesis plays a critical role in normal ovarian physiology, as well as in the pathogenesis of ovarian cancer. VEGF is the bestcharacterized angiogenic factor and is recognized as a major element in regulating angiogenesis. ${ }^{5}$ Increased VEGF expression has been associated with the development of tumor progression and poor OS. ${ }^{6}$

As the first approved anti-VEGF drug for treatment of EOC by the US Food and Drug Association, bevacizumab is the most widely studied. Most recently, five Phase III RCTs have been carried out. Although all studies reported prolonged PFS, only two suggested an improvement in OS among predefined subgroups in exploratory analyses.
Furthermore, the optimal chemotherapy regimen in combination with bevacizumab remains uncertain.

In this meta-analysis, we pooled the results of PFS and OS from these five Phase III RCTs. The PFS results showed that the addition of bevacizumab to chemotherapy offers meaningful improvement in PFS in EOC treatment $(\mathrm{HR}=0.63$, $P<0.01)$. Although four of five studies met their primary endpoints of prolonging PFS, none of the studies demonstrated improvements in OS among enrolled populations that were not designed to detect a difference in OS. The other trial, GOG-0213, in which the primary endpoint was OS, showed results that were close to statistical significance for OS (adjusted HR $=0.829 ; 95 \%$ CI, 0.683-1.005; $P=0.056$ ).

A

\begin{tabular}{lll}
$\begin{array}{l}\text { Study or } \\
\text { subgroup }\end{array}$ & Log (hazard ratio) & SE \\
\hline PC-based & & \\
GOG-0218 10,11 & -0.2614 & 0.0627 \\
ICON7 $7^{12,20}$ & -0.2107 & 0.0745 \\
GOG-0213 & -0.4878 & 0.0828 \\
Subtotal (95\% CI) & \\
Heterogeneity: $\tau^{2}=0.01 ; \chi^{2}=6.96, d f=2(P=0.03) ; I^{2}=71 \%$ \\
Test for overall effect: $Z=4.00(P<0.0001)$
\end{tabular}

\section{PFS}

Weight Hazard ratio IV, Hazard ratio IV,

random, $95 \% \mathrm{Cl} \quad$ random, $95 \% \mathrm{Cl}$

$\begin{array}{lll}\text { Non-PC-based } & & \\ \text { OCEANS } & & \\ \text { AURELIA } & & \\ \text { AU,21 } & -0.7257 & 0.1128 \\ \text { Subtotal }(95 \% \mathrm{Cl}) & -0.734 & 0.1192 \\ \text { Heterogeneity: } \tau^{2}=0.00 ; \chi^{2}=0.00, d f=1(P=0.96) ; I^{2}=0 \% \\ \text { Test for overall effect: } Z=8.91(P<0.00001)\end{array}$

Total $(95 \% \mathrm{Cl})$

Heterogeneity: $\tau^{2}=0.04 ; \chi^{2}=28.58, d f=4(P<0.00001) ; I^{2}=86 \%$

Test for overall effect: $Z=4.55(P<0.00001)$

Test for subgroup differences: $\chi^{2}=13.37, d f=1(P=0.0003) ; I^{2}=92.5 \%$

B

Study or
subgroup

21.8

21.1

20.6

63.5

$.77(0.68,0.87)$

$0.81(0.70,0.94)$

$0.61(0.52,0.72)$

$0.73(0.63,0.85)$

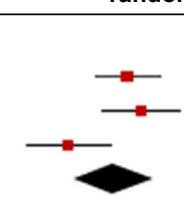

\section{PC-based}

GOG-0218 10,1

ICON7 $7^{12,20}$

GOG-0213 3

$-0.0101$

$-0.19$

Subtotal $(95 \% \mathrm{Cl})$

Heterogeneity: $\chi^{2}=2.24, d f=2(P=0.33) ; I^{2}=11 \%$

Test for overall effect: $Z=1.91(P=0.06)$

Non-PC-based

OCEANS ${ }^{14,19}$

AURELIA ${ }^{13,21}$

$-0.0492$

$-0.1625$

0.1076

Subtotal $(95 \% \mathrm{CI})$

Heterogeneity: $\chi^{2}=0.45, d f=1(P=0.50) ; I^{2}=0 \%$

Test for overall effect: $Z=1.16(P=0.25)$

Total $(95 \% \mathrm{Cl})$

100

$0.91(0.84,0.99)$

Heterogeneity: $\chi^{2}=2.70, d f=4(P=0.61) ; I^{2}=0 \%$

Test for overall effect: $Z=2.24(P=0.03)$

Test for subgroup difference: $\chi^{2}=0.00, d f=1(P=0.99) ; I^{2}=0 \%$

$0.63(0.51,0.77)$

18.5

18.0

36.5

$0.48(0.39,0.60)$

$0.48(0.38,0.61)$

$0.48(0.41,0.57)$

$15.5 \quad 0.95(0.77,1.18)$

$10.8 \quad 0.85(0.66,1.09)$

$26.3 \quad 0.91(0.77,1.07)$

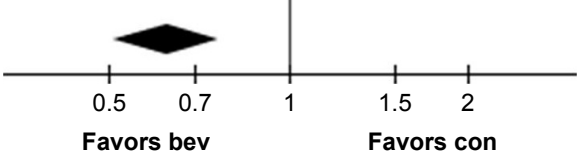

OS

Hazard ratio IV, Hazard ratio IV,

$0.88(0.75,1.04)$

$0.99(0.85,1.15)$

$0.83(0.68,1.00)$

$0.91(0.83,1.00)$
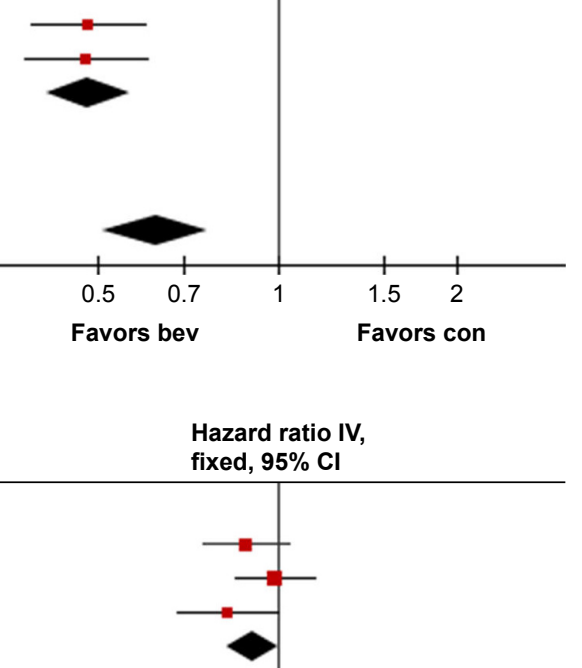

Figure 3 (Continued) 
C

Study or

subgroup

PC-based

GOG-0218 10,1

ICON7 $7^{12,20}$

GOG-0213 3

Subtotal $(95 \% \mathrm{Cl})$

Heterogeneity: $\tau^{2}=0.01 ; \chi^{2}=6.96, d f=2(P=0.03) ; I^{2}=71 \%$

Test for overall effect: $Z=4.00(P<0.0001)$

Non-PC-based

AURELIA ${ }^{13,21}$

$-0.7257$

$-0.734$

0.1128

0.1192

18.5

18.0

36.5

PFS

Subtotal $(95 \% \mathrm{Cl})$

$\chi^{2}=0.00, d f=1(P=0.96) ; I^{2}=0 \%$

Weight Hazard ratio IV,

random, $95 \% \mathrm{CI}$

Hazard ratio IV,

(\%)

$0.77(0.68,0.87)$

$\begin{array}{ll}21.8 & 0.77(0.68,0.87) \\ 21.1 & 0.81(0.70,0.94)\end{array}$

$20.6 \quad 0.61(0.52,0.72)$

$63.5 \quad 0.73(0.63,0.85)$

Heterogeneity: $\tau^{2}=0.00 ; \chi^{2}=0.00, d f=1(P=0.8$
Test for overall effect: $Z=8.91(P<0.00001)$

Total $(95 \% \mathrm{Cl})$

100

$0.63(0.51,0.77)$

Heterogeneity: $\tau^{2}=0.04 ; \chi^{2}=28.58, d f=4(P<0.00001) ; I^{2}=86 \%$

Test for overall effect: $Z=4.55(P<0.00001)$

Test for subgroup differences: $\chi^{2}=13.37, d f=1(P=0.0003) ; I^{2}=92.5 \%$

$0.48(0.39,0.80)$

$0.48(0.38,0.61)$

$0.48(0.41,0.57)$

random, $95 \% \mathrm{Cl}$

Study or

subgroup

PC-based

GOG-0218 10,11

ICON7 $7^{12,20}$

GOG-0213 3

Subtotal $(95 \% \mathrm{Cl})$

Heterogeneity: $\chi^{2}=0.28, d f=2(P=0.87) ; I^{2}=0 \%$

Test for overall effect: $Z=2.82(P=0.005)$

Non-PC-based

OCEANS ${ }^{14,19}$

AURELIA ${ }^{13,21}$

$-0.0492$

$-0.1625$

0.1076

18.0

12.5

30.5

$0.95(0.77,1.18)$

Subtotal $(95 \% \mathrm{CI})$

Heterogeneity: $\chi^{2}=0.45, d f=1(P=0.50) ; I^{2}=0 \%$

Test for overall effect: $Z=1.16(P=0.25)$

Total $(95 \% \mathrm{Cl})$

Heterogeneity: $\chi^{2}=1.09, d f=4(P=0.90) ; I^{2}=0 \%$

Test for overall effect: $Z=2.99(P=0.003)$

Test for subgroup differences: $\chi^{2}=0.35, d f=1(P=0.55) ; I^{2}=0 \%$

100

$0.87(0.80,0.95)$

$0.91(0.77,1.07)$

OS

Hazard ratio IV, Hazard ratio IV

fixed, $95 \% \mathrm{Cl}$

Figure 3 Forest plots of hazard ratios for progression-free survival ( $\mathbf{A}$ and $\mathbf{C}$ ) and overall survival (B and $\mathbf{D}$ ). In patients with epithelial ovarian cancer treated with bevacizumab plus chemotherapy, compared with chemotherapy alone, as chemotherapy regimens of carboplatin plus paclitaxel or not (A and B). In patients with epithelial ovarian cancer with high risk of progression (FIGO stage IV disease or FIGO stage III disease and $>$ I.0 cm of residual disease after debulking surgery) treated with bevacizumab plus chemotherapy, compared with chemotherapy alone, as chemotherapy regimens of carboplatin plus paclitaxel or not (C and D).

Abbreviations: $\mathrm{Cl}$, confidence interval; PC, paclitaxel and carboplatin; PFS, progression-free survival; OS, overall survival; bev, bevacizumab; con, control; FIGO, International Federation of Gynecology and Obstetrics; IV, inverse variance.

However, the results of OS in this meta-analysis showed that the addition of bevacizumab to chemotherapy offered significant improvement in EOC treatment $(\mathrm{HR}=0.91, P<0.05)$. These results confirmed the hypothesis of many researchers that the 5-month improvement associated with bevacizumab is both a clinical and a statistical improvement. ${ }^{3}$

In addition, combinations with chemotherapy regimens are controversial with respect to OS. Whether PC is better than other chemotherapeutic agents as a companion for bevacizumab remains a critical question. In this meta-analysis, the subgroup analysis based on the regimen of chemotherapy showed that the addition of bevacizumab to chemotherapy for EOC led to a statistically significant improvement in PFS, both in PC-based chemotherapy ( $\mathrm{HR}=0.73, P<0.01$ ) and in non-PC-based chemotherapy ( $\mathrm{HR}=0.48, P<0.01$ ). Regarding OS, the subgroup that received a combination of bevacizumab and different regimens of chemotherapy showed a trend of improvement, but these trends were not statistically significant for two regimens of chemotherapy (HR $=0.91$, $P=0.07$ for $\mathrm{PC}$-based chemotherapy; HR $=0.91, P=0.25$ for 

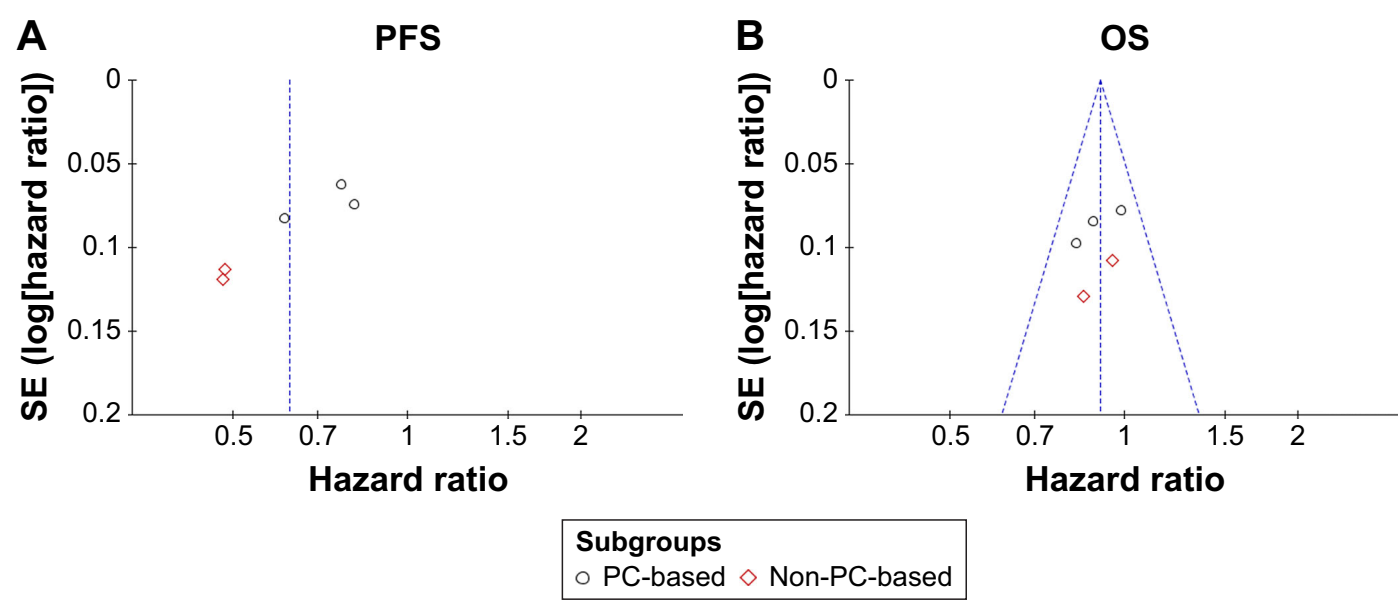

Figure 4 Funnel plots of hazard ratios for progression-free survival (A) and overall survival (B).

Abbreviations: PFS, progression-free survival; OS, overall survival; SE, standard error; PC, paclitaxel and carboplatin.

non-PC-based chemotherapy). However, the results are different from OS among high-risk subgroups in exploratory analyses. In first-line treatment, the results of two trials (GOG0218 and ICON7) showed a much greater survival benefit in patients with a high risk of progression (FIGO stage IV or III disease and $>1.0 \mathrm{~cm}$ of residual disease after debulking surgery). We also pooled the PFS or OS of this population in subgroup analysis, as presented in Figure $3 \mathrm{C}$ and D. The results showed that whether the chemotherapy was PC-based or not, PFS exhibited significant improvement (HR $=0.73$, $P<0.01$ for PC-based chemotherapy; $\mathrm{HR}=0.48, P<0.01$ for non-PC-based chemotherapy). Interestingly, the subgroup that received a combination of bevacizumab and different regimens of chemotherapy showed a significant improvement in PC-based chemotherapy ( $\mathrm{HR}=0.86, P<0.01$ ), but not in non-PC-based chemotherapy ( $\mathrm{HR}=0.91, P>0.05)$ in patients with a high risk of progression in OS. The prior results suggested that non-PC-based chemotherapy is better than PCbased chemotherapy at improving survival in populations with a high risk of progression. The later results suggested that PCbased chemotherapy regimens were the best chemotherapy regimens when in combination of bevacizumab, which was supported by the ICON 6 study. ${ }^{22}$ This requires prospective validation in further studies.

\section{Strengths and limitations}

Our study had several advantages. The data collected from five large, multicenter Phase III trials were sufficiently powered to test the efficacy and safety of treatment with bevacizumab. All the studies included in this review were well-designed and of high quality. This study, however, also has some limitations. First, only five trials were found to meet the eligibility criteria. Unpublished trials with negative results may have been performed, despite the extensive search of all relevant references. Furthermore, trials in this meta-analysis included different patient populations, lines of treatment, doses of bevacizumab, concurrent chemotherapies, follow-up durations, and lengths of bevacizumab maintenance. Lastly, this meta-analysis pooled the data rather than assessing individual trials.

\section{Conclusion}

The combination of bevacizumab with a PC-based regimen offers a new treatment option for patients with EOC, especially in those with a high risk of progression.

\section{Acknowledgments}

This work was supported by grants from the Natural Science Foundation of Fujian (No 2014J01278), the Science Foundation for The Excellent Youth and Middle-aged Scholars of the Health System of Fujian (No 2014-ZQN-ZD-5), and the Science Foundation for Youth Scholars of Medicine and Health of Fujian (No 2015-1-16).

\section{Disclosure}

The authors report no conflicts of interest in this work.

\section{References}

1. Chen W, Zheng R, Baade PD, et al. Cancer statistics in China, 2015 CA Cancer J Clin. 2016;66:115-132.

2. Siegel RL, Miller KD, Jemal A. Cancer statistics, 2016. CA Cancer J Clin. 2016;66:7-30.

3. Coleman RL, Brady MF, Herzog TJ, et al. Bevacizumab and paclitaxelcarboplatin chemotherapy and secondary cytoreduction in recurrent, platinum-sensitive ovarian cancer (NRG Oncology/Gynecologic Oncology Group study GOG-0213): a multicentre, open-label, randomised, phase 3 trial. Lancet Oncol. 2017;18:779-791. 
4. Monk BJ, Minion LE, Coleman RL. Anti-angiogenic agents in ovarian cancer: past, present, and future. Ann Oncol. 2016;27 (Suppl 1): i33-i39.

5. Garcia AA, Hirte H, Fleming G, et al. Phase II clinical trial of bevacizumab and low-dose metronomic oral cyclophosphamide in recurrent ovarian cancer: a trial of the California, Chicago, and Princess Margaret Hospital Phase II consortia. J Clin Oncol. 2008;26:76-82.

6. Graybill W, Sood AK, Monk BJ, Coleman RL. State of the science: emerging therapeutic strategies for targeting angiogenesis in ovarian cancer. Gynecol Oncol. 2015;138:223-226.

7. Mabuchi S, Terai Y, Morishige K, et al. Maintenance treatment with bevacizumab prolongs survival in an in vivo ovarian cancer model. Clin Cancer Res. 2008;14:7781-7789.

8. Monk BJ, Choi DC, Pugmire G, Burger RA. Activity of bevacizumab (rhuMAB VEGF) in advanced refractory epithelial ovarian cancer. Gynecol Oncol. 2005;96:902-905.

9. Monk BJ, Han E, Josephs-Cowan CA, Pugmire G, Burger RA. Salvage bevacizumab (rhuMAB VEGF)-based therapy after multiple prior cytotoxic regimens in advanced refractory epithelial ovarian cancer. Gynecol Oncol. 2006;102:140-144.

10. Burger RA, Sill MW, Monk BJ, Greer BE, Sorosky JI. Phase II trial of bevacizumab in persistent or recurrent epithelial ovarian cancer or primary peritoneal cancer: a Gynecologic Oncology Group Study. J Clin Oncol. 2007;25:5165-5171.

11. Burger RA, Brady MF, Bookman MA, Fleming GF, Monk BJ, Huang H. Incorporation of bevacizumab in the primary treatment of ovarian cancer. N Engl J Med. 2011;365:2473-2483.

12. Perren TJ, Swart AM, Pfisterer J, et al. A phase 3 trial of bevacizumab in ovarian cancer. $N$ Engl J Med. 2011;365:2484-2496.

13. Pujade-Lauraine E, Hilpert F, Weber B, et al. Bevacizumab combined with chemotherapy for platinum-resistant recurrent ovarian cancer: The AURELIA open-label randomized phase III trial. J Clin Oncol. 2014; 32:1302-1308.
14. Aghajanian C, Blank SV, Goff BA, et al. OCEANS: a randomized, double-blind, placebo-controlled phase III trial of chemotherapy with or without bevacizumab in patients with platinum-sensitive recurrent epithelial ovarian, primary peritoneal, or fallopian tube cancer. J Clin Oncol. 2012;30:2039-2045.

15. Moher D, Liberati A, Tetzlaff J, Altman DG. Preferred reporting items for systematic reviews and meta-analyses: the PRISMA statement. PLoS Med. 2009;6:e1000097.

16. Higgins JP, Altman DG, Gotzsche PC, et al. The Cochrane Collaboration's tool for assessing risk of bias in randomised trials. $B M J$. 2011;343:d5928.

17. DerSimonian R, Laird N. Meta-analysis in clinical trials. Control Clin Trials. 1986;7:177-188

18. Higgins JP, Thompson SG, Deeks JJ, Altman DG. Measuring inconsistency in meta-analyses. BMJ. 2003;327:557-560.

19. Aghajanian C, Goff B, Nycum LR, Wang YV, Husain A, Blank SV. Final overall survival and safety analysis of OCEANS, a phase 3 trial of chemotherapy with or without bevacizumab in patients with platinum-sensitive recurrent ovarian cancer. Gynecol Oncol. 2015;139: $10-16$.

20. Oza AM, Cook AD, Pfisterer J, et al. Standard chemotherapy with or without bevacizumab for women with newly diagnosed ovarian cancer (ICON7): overall survival results of a phase 3 randomised trial. Lancet Oncol. 2015;16:928-936.

21. Poveda AM, Selle F, Hilpert F, et al. Bevacizumab combined with weekly paclitaxel, pegylated liposomal doxorubicin, or topotecan in platinumresistant recurrent ovarian cancer: analysis by chemotherapy cohort of the randomized phase III AURELIA trial. J Clin Oncol. 2015;33: 3836-3838.

22. Ledermann JA, Embleton AC, Raja F, et al. Cediranib in patients with relapsed platinum-sensitive ovarian cancer (ICON6): a randomised, double-blind, placebo-controlled phase 3 trial. Lancet. 2016;387: 1066-1074.
OncoTargets and Therapy

\section{Publish your work in this journal}

OncoTargets and Therapy is an international, peer-reviewed, open access journal focusing on the pathological basis of all cancers, potential targets for therapy and treatment protocols employed to improve the management of cancer patients. The journal also focuses on the impact of management programs and new therapeutic agents and protocols on

\section{Dovepress}

patient perspectives such as quality of life, adherence and satisfaction. The manuscript management system is completely online and includes a very quick and fair peer-review system, which is all easy to use. Visit http://www.dovepress.com/testimonials.php to read real quotes from published authors. 